\title{
The Health Care Management of Auditory Discrimination in Grade IV and V Pupils
}

\author{
Ching-Yuan Chen \\ Central Taiwan University of Science and Technology \\ E-Mail: cychen3@ctust.edu.tw \\ Yen-Yi Chung* \\ Central Taiwan University of Science and Technology \\ E-Mail: yychung101940@ctust.edu.tw \\ Wan-Lin Wang \\ Central Taiwan University of Science and Technology \\ E-Mail:106566@ctust.edu.tw
}

\begin{abstract}
This study was first to be conducted using the Auditory Test made by Dr. Gloria C. Rigonan, Division Music Supervisor, Division of Cavite. The appreciation of music maybe defined as the acquired ability to listen to music intelligently. Although people have aptitudes in the musical perceptiveness, no one is born with this ability, it is acquired. Conscious effort is at all times necessary in the exercise of intelligent listening. We will be concerned, therefore with the means by which you can acquire the ability to listen to music intelligently. This study was confined to the measurement of auditory discrimination of 110 pupils selected at random from the enrollment in Grade IV and V inclusive in the school. Each grade was selected at random, 55 pupils from each grade level. The respondents for this study were selected at random by getting the $20 \%$ of the total population of Grades IV and V respectively. The Auditory test by Dr. Gloria C. Rigonan was used in this study. This investigation aimed to compare the musical abilities of pupils in auditory discrimination. Its principal aim was to determine the status of pupils' achievement on auditory discrimination. To solve the problem, the researcher made use of Authority Test made by Dr. Gloria C.
\end{abstract}

*Corresponding author 
Rigonan, Division Music Supervisor, Division of Cavite, with proper guidance and permission asked from her by the researcher. In as much as there is no relationship in the achievement in auditory discrimination that existed between the musical interest and mental ability of the pupils any child therefore can be helped to develop the proper musical interest to achieve the goals of music education in the elementary level. In as much as the findings of this study were not conclusive, the following are recommended: A similar study in a different environment; A replication of the study, using the following variables; high mental ability, high socio-economic status and high interest in music. Similar studies using age and sex as the variables correlated with musical interest. Strengthen the music education awareness in college in adequately prepare this would be teachers to teach music correctly and effectively.

Keywords: Auditory Discrimination, Auditory Test, Grade IV and V Pupil

\section{INTRODUCTION}

Music is fundamental in the education of every child. Great emphasis has been placed on the importance of music by great educators and philosophers on their teachings and philosophies. Aristotle saw in music not only a release from tension, disturbed emotional state but also recreation, enjoyment and relaxation which is very necessary for the positive development of character.

The importance of music in the education of the children had been recognized by people of all times. Musical training is a more potent instrument than any other, because rhythm and harmony find their way into the inward places of the soul in which they mightily fasten imparting grace.

They intend it as a great compliment when they say that they are good listeners. They mean that they not only listen passively to what they are telling him that he enters actively into their tale, drawing him out, making him want to continue, somehow grasping the meaning behind the words. They very fact that they singled out certain people as good listeners make it clear not only in the art of listening everyone has mastered.

The same goes to music. It is not enough to be in the room with the sound, or listen intermittently while one's thoughts wonder hither and yon. To listen perceptively requires that one fastens his whole attention upon the sounds as they come floating through the air, that he observes the pattern they form, and responds to the well springs of thought and feeling out of which pattern has emerged.

It is idle to classify the listening experience as being the sensual, the emotional, 
or the intellectual level. Today, it is recognized that such categories are extremely fluid. People listen differently to different kinds of music and hear the same piece differently on different occasions. As new comers to music; they fall into the way of listening that comes natural to them. With practice and experience they learn other way. The goal of training in the art of listening must be to unite all three levels so that they will apprehend the floating patterns of sounds with all the joys of our senses, the freshness of our emotions, the power of our understanding. When one completely understands a great work of music, he grasps the "moment of truth" that gave its birth. In effect, he listens perceptively, and that is one sure road to the enjoyment of music.

Still there are ways of listening that will permit anyone to hear music, better, to glimpse the unexpected visits the great literature of music, and to enjoy more fully the immense variety of emotions hidden in its depths. The shades of tone color of individual voices or instruments in the orchestra maybe a source of delight. Some listeners confess to listening music entirely this way; and some translating sound into a spectrum of the color. An individual is often stirred by the rhythmic animation and drive of music; by sudden contrast of loud and soft, by the excitement of crescendo or even by the suspense of a dramatic silence.

The intellectual and aesthetic appreciation of music has always been the concern of the educators. This is proven by the fact that it is taught in all schools. It is believed that youth must be taught how to discriminate music from noise.

The pupil should achieve the capacity to discriminate among musical compositions of all types. He should be responsive to expressive qualities, which maybe found in jazz dances as well as in serious masterworks; he should be responsive to both traditional and contemporary editions.

The trained listener hears music and experiences it according to his emotional capacity which is different from the untrained listeners. Even with relatively familiar music, a listener must be prepared to take alert and informed attitude toward listening in order to absorb a composition to its greatest advantage. This is no single road to understanding music but certain attitudes are essential. In short, music should be listened to attentively. It should be listened to as a whole.

Music is a vitalizing factor for the other subjects in the curriculum. Of all the arts, music is of the most difficult to discuss. It is a complicated matter to define; something that cannot be seen or touched but only heard and felt. Yet as a prescribed subject, it seems to be neglected especially by the teachers who are less interested in music. With six (6) units in music taken in college, they teach haphazardly or they skip the music period. This occurrence may be due to the teacher who has no liking 
for music or who teaches just for the sake of monetary reasons. It can also be attributed to the short time assigned to music which was paired with writing several years ago.

This, study, therefore, has undertaken by the researcher because as a music teacher, she is aware of the most important role of music to the life of a man. She also wants to discover from her study the achievement level of pupils in auditory discrimination and how well this study could also help inculcate the hidden talents of pupils when it comes to listening in music. Also as a music teacher for almost ten years, she wants to find out on what aspect of listening to music do pupils fluctuate so as to give prior remedies on how this side of music could be more enriched. Appreciable improvement can be expected with the proper kind of training given by the teachers on the basis of the talents and abilities manifested by the listeners and learners.

\section{THEORETICAL FRAMEWORK}

An effective music education in the elementary school should be based on a cumulative sequence of musical understanding. Individual classes vary greatly in musical aptitude and attainment. This instruction must always be adjusted to the children's present stage of development in his class achieved and select the materials and learning experiences that will suit the children's needs and capabilities (Bergethon, Boardman, and Montgomery, 1986). It is important for the music teacher to have some knowledge of the existing test in the field. Test may give considerable help in deciding as to the innate musical ability of the individual pupils or at least they may help to decide upon the extent to which he possesses certain abilities such as keen sense of relative pitch, a developed feeling of tonality so forth that seems important in musical ability.

Listening to music seems prerequisite to all other musical pursuits. Discrimination is the basic for listening. The first level of discriminatory perception is whether music is being heard. Background music exists in our culture in large proportions, and most people are being conditioned to being bathed in sound. Listening to music, as far as the educator is concerned, should transcend this "on-off" level and include additional discrimination. An old clincher states that "all life is like a bath, once gets used to it, its not hot." Perhaps this is especially applicable to music. There seem to be many people who enjoy listening to music, but their attention wanes appreciably after the initial stimulus and they prefer to daydream and drift with a mood. Mood affects also extremely desirable and are very important in music 
education, but these experiences should not be confused with developing listening skills.

Partial answer to questions concerned with enhancing the listening experience might lie in investigations that attempt to test the effects of different types of successive programs aimed at teaching effective discrimination. One such program might experiment with two pitches contrasting the differences of the two sounds. As successive pitches are presented, the elementary concept of introducing form might be investigated. For example, one might start with one pitch goes to two, to three, to a group, to a phrase, to a melody, to an embalmment of the same melody (variation form), then to a different melodies (binary form). The melody could be presented to the chase itself (canon) and to chase itself with the same melody at a different interval. The simple form songs could be extended to encompass larger forms sonata, rondo, etc.). This process could provide many experiments concerning to development of discrimination skills.

Another approach could experimentally test effective discrimination programs involving the differentiation of the composite sounds of an ensemble. The pupils could be given something specific to listen for (high-low, loud-soft, fast-slow, short-long) and progress to greater discriminations, for example Tuttle concertino, string winds, string brass, trumpets-trombones, trumpet-orns, trumpets-trumpets) with the experimenter testing effective discrimination presentations. This approach might gradually encompass subtleties of the orchestration with experimental verification. Another program might concentrate on the awareness of specific motifs, both rhythmic and harmonic testing the subtle discrimination in harmony and style (Theoretical analysis).

\section{STATEMENT OF THE PROBLEM}

The purpose of this study is to determine the achievement level of pupils in auditory discrimination of a group of boys and girls at various age from Grades IV and V in Silang Central School, District of Silang Division of Cavite.

Specifically, the study attempts to answer the following questions:

1. What is the profile of Grade IV and V pupils in terms of: age, mental ability, socio-economic status and pupils interest in music?

2. What is the performance level of Grade IV and V pupils in auditory discrimination?

3. Is there a significant difference between the Grade IV and V pupils in auditory discrimination? 
4. Is there a significant relationship between the Grade IV and V pupils achievement in auditory discrimination in relation to some psychosocial variables?

\section{HYPOTHESIS}

To answer the question raised in this study the following hypothesis were tested:

1. There is no significant difference between the Grades IV and V pupils in auditory discrimination.

2. There is no significant relationship between the Grade IV and V pupils achievement in auditory discrimination in relation to some psychosocial variables.

\section{SIGNIFICANCE OF THE STUDY}

It seemed that Philippine schools have been carrying on music education programs without benefit of knowing how much the objectives in the area had been achieved. This did not discount the fact that teachers had been constructing daily and unit achievement test and a few researchers had developed achievement tests in some areas of music. But this seemed to have no norms to which they could compare the achievement of their school children. This study therefore hopes to fulfill these needs. With the norms established in pitch, interval, meter, and tones any teacher might avail the same test use here would have a basis for comparison of the observed scores of their pupils. Individual teaching of school music programs along the same areas could be assessed. It could seem that this study might reveal the extent of teaching pitch, interval, meter and tone made the first four grades of pupils in the research.

\section{REVIEW OF RELATED LITERATURE AND STUDIES}

This study was first to be conducted using the Auditory Test made by Dr. Gloria C. Rigonan, Division Music Supervisor, Division of Cavite. However, the writer relates her study based on the following: The appreciation of music maybe defined as the acquired ability to listen to music intelligently. Although people have aptitudes in the musical perceptiveness, no one is born with this ability, it is acquired. Conscious effort is at all times necessary in the exercise of intelligent listening. We will be concerned, therefore with the means by which you can acquire the ability to listen to music intelligently. Although people have aptitudes in the musical perceptiveness, no one is born with this ability, it is acquired. Conscious effort is at al times necessary in the exercise of intelligent listening. We will be concerned, therefore with the means by which you can acquire the ability to listen intelligently. The development of the child 
is best indicated by the attainment of readiness to learn or sufficient maturity to profit from normal instruction in the school situation as emphasized by Kelly (1982) in his book. He further discussed that although not all children who enter school at the required are equally ready, learning can take place only when readiness has been attained by the child.

Furthermore, he stated that the readiness of an individual as the entered school maybe due to proper physical, emotional and mental development, experimental background, interest and willingness to learn. Hence the age limits of the elementary school period are determined by modern educational practice. Customarily, the child enters school at the age of seven years and progress through Grade I and IV at the one grade level per year. Age is believed to be one of the factors that would affect the child's achievement in school. It is pertinent to stress that in our educational system, pupils are classified according to age, or by grade level. Garry and Kingsley (1970), stressed that age should not be overlooked nor ignored if we would like the children to learn. They explain further that the older person has the greater ability to sustain attention, follow instruction and maintain a given value, if given or administered reaction-type problem. In the study made by Yotonghot (1986), on the age and performance level in the NFE program of the refugees in Thailand revealed that the common education of the students enrolled is composed of age 15 to 19 teenagers and 20 years and above or adults. Likewise, Samonte (1990), her study revealed that 55\% of the students were within normal age while $25 \%$ were 15 years old and above. Others, which is 20 percent belonged to group of 13 years old and below.

Drake (1980) found factors necessary for music as music memory items or ear-mindedness. Other important factors according to him were pitch discrimination, sense of rhythm, musical intelligence, muscular skill and fine neuromuscular coordination. Freedom (1980), describes sex as an attribute of mature affect ional life of an adult which forms the basis of a satisfying home life and the building of responsible family of men and women. Thus, from the readings described, sex exerts an important influence upon the individuals' adjustment; he must fit sex harmoniously into his personality and philosophy of life. The study of Miner (1968), on sociological background affecting school achievement revealed that difference on parents occupational status contribute to differentiate achievement.

Once more in the study conducted by Samonte (1990), she revealed that father's occupational status affects the achievement of the students. Fathers who have permanent jobs, regardless of what type, have children with high and average performance. Likewise, students whose parents have high earnings achieved higher 
than those with parents having low earnings. Socio-economic status and taste in music are related as studied by Schwessier who concluded that musical taste of thousand subjects was concluded by their socio-economic background, specifically by their occupations.

Interest and success in music are in general related positively to personality and social adjusted as studied by Rughes who used ratings, socio-grams and the California Test of personality to grade three, five seven, nine and eleven children. His findings revealed that the extent of the contribution of musical activities play a substantial role to social adjustments (Marvin, Alkin, and Karen, 1992). Juan (1980), in her study of the music education program in Pasig, Division of Quezon City, found that the Pupils performance were not favorable in all the six schools under the study which resulted to her suggestion for music teachers to find means to arouse the interest of pupils in learning music.

\section{RESEARCH METHOD}

The descriptive survey method was used in the study. This procedure calls for study of existing conditions at the time this study was made. Furthermore, it requires extensive use of techniques which are essential for measuring and recording variables necessary for the study. In this case, the writer used the Achievement Test made by Dr. Gloria C. Rigonan. The test is on auditory discrimination in tape with Filipino as medium in giving instructions. The test measures accuracy in judgment of variations in tone interval, time, mode and rhythm. The talent for various elements was tested in the following manner: Tonal discrimination - pupils listened to tunes on tapes and identified whether the following tunes are low, high of the same tune. Interval discrimination - pupils listened to tunes of different interval and they identified the interval of tunes. They referred their answer to the answer sheet. Mode discrimination - pupils were given test on major keys and minor keys and they were asked to determine if the tunes were in the minor or major keys. Discrimination on rhythm - pupils were given scores of songs and they compared it with the rhythms heard. They identified which measures are wrong.

\section{Methods Used in Gathering the Data}

As stated previously, this study made use of the descriptive method o survey. The problems were approached by giving the auditory test by Dr. Gloria C. Rigonan. The test was secured from her. After having granted due permission, the writer scheduled the administration of the tests to 100 Grades IV and V pupils. 


\section{SUMMARY OF FINDINGS, CONCLUSIONS AND RECOMMENDATIONS}

The data and information used to answer the basic questions raised in this study were gathered through locally constructed questionnaires: one on musical interest. Mental ability test of the respondents were gathered through the use of the Otis-Lennon Mental Ability Test for Elementary I and II (OLMAT) and Auditory Discrimination Test on tape by Dr. Gloria C. Rigonan. To provide consistency and brevity in discussion, this chapter is subsided into four correlatives of arts to wit:

Part One - presented the profile of the respondent which includes: age, sex, mental ability, socio-economic status and musical interest.

Part Two - discussed the performance level of Grade IV and V pupil in auditory discrimination.

Part Three - deals on the significant difference in auditory discrimination when pupils are grouped by grade assignment.

And lastly, Part Four- deals on the significant relationship between Grades IV and $\mathrm{V}$ pupils achievement in auditory discrimination in each of the following factors: age, sex, socio-economic status, pupils interest in music and mental ability.

The following hypothesis was for the acceptance or rejection in this study:

1. There is no significant difference between the Grade IV and V pupils in auditory discrimination.

2. There is no significant relationship between the Grade IV and V pupils achievement in auditory discrimination in relation to some psychological variables.

This study utilized the descriptive method of research, the data were gathered through the use of a questionnaire answered by one hundred ten (110) respondents consisting of fifty-five (55) grade four pupils and fifty five (55) grade $\mathrm{V}$ pupils purposively selected, weighted means t-test of significant differences and chi-square test for significant relationship.

\section{Summary of Findings}

On the basis of gathered data in terms of the statement of the problem, the following were the significant findings:

1. Profile of the Respondents

- Sex

The respondents were male and female from Grade IV and V in Silang 
Central School. Male respondents from Grade IV were $25.45 \%$ and $24.55 \%$ were female while $24.55 \%$ were male and 25.45 were female from the grade $\mathrm{V}$ respondents.

- Age

The age of the respondents ranged from 9 to 13 years and above. Study four or $58.18 \%$ of the respondents belonged to 9-10 age group.

- Mental Ability

The respondent's mental ability varies from poor to superior. It shows that majority of the respondents have average mental ability which is 71 or 64.54 $\%$.

- Socio-economic Status

Thirty seven or $33.64 \%$ of the respondents belonged to low average income.

- Musical Interest

The Grade IV pupil was fairly interested in all musical aspects with a weighted average of 3.48 while the Grade V pupils were interested with a weighted average of 3.50 .

2. Performance Level in Auditory Discrimination

- Tone

In tone the Grade IV pupils have an average level with a mean score of 9.55 while the Grade $\mathrm{V}$ pupils have a good performance level with a mean score of 10.22.

- Interval

In interval, the Grade IV has average level with a mean score of 10.16 while the Grade V has good level of performance with a mean score of 10.4.

- Time

The Grade IV respondents were superior with a mean score of 11.18 while the Grade V was low average with a mean score of 7.93 .

- Mode

The Grade IV respondents were poor in performance with a mean score of 6.47 while the Grade V were excellent in performance wit a mean score of 10.93.

- Rhythm

The Grade IV respondents were poor in performance level with a mean score of 6.09 while the Grade $\mathrm{V}$ respondents were low average a mean score of 6.56 . 
3. Significant Difference between Grade IV and V Pupils Achievement in Auditory Discrimination.

The respondents computed $\mathrm{t}$-value $(\mathrm{t}=1.26)$ in tone discrimination, $(\mathrm{t}=0.54)$ in interval discrimination, $(\mathrm{t}=1.02)$ in rhythm discrimination which is lower than the value of $t$ at 0.05 level of significance revealed that there is no significant differences that existed between the achievements of the two respondents. On the other hand, the computed $t$-value $(t=6.37)$ in time discrimination and $(t=8.75)$ in mode discrimination which is higher than the value of $t$ at 0.05 level of significance revealed that there is significant differences that existed between the achievement of the two respondents.

4. Relationship between the Grade IV and V Pupils' Achievement in Auditory Discrimination in Relation to Some Psychological Variables.

- Mental Ability

The chi-square test revealed that mental ability of the respondents was related to the achievement level in auditory discrimination as evidence by a chi-square value of 130.01. Scrutinizing the table revealed that most of the respondents being to average mental ability.

- Socio-economic Status

There is a significant relationship that existed between the respondent's achievement in auditory discrimination and socio-economic status as revealed by the chi-square test of value of 69.92 . It could be noted from the table that most of the respondents of 37 or 33.64 percent were of low average income.

- Musical Interest

Based on the chi-square value of 19.65 no significant relationship was found between the respondents' achievement in auditory discrimination and musical interest.

\section{Conclusions}

In this study therefore, the researcher concluded that the Grade V pupils were excellent in mode discrimination, average in interval discrimination, low average in time and rhythm discrimination and good in tone discrimination, good in interval discrimination, average in tone discrimination and poor both in mode and rhythm discrimination. No significant differences existed between the achievement of Grade $\mathrm{IV}$ and $\mathrm{V}$ tone, interval and rhythm discrimination, while significant differences existed between the respondents achievement in time and mode discrimination. With regards to the significant relationship of some psychological variables to the 
achievement in auditory discrimination of the respondents, musical interest has no significant relationship while the mental ability and socio-economic status of the respondents has significant relationship in the achievement of the respondents in auditory discrimination. Therefore, the socio-economic status of the respondents greatly affected their achievements because they lacked musical materials at home and made them unaware of the musical tunes that they heard during the administration of auditory test. Also, most of the respondents who come from low income do not possess any musical materials wherein they can listen to in order to be aware of the musical tunes when they are in school. On the other hand, the mental ability of the respondents also affects the achievement level of auditory discrimination because majority of the respondents fall on average level of mental ability.

\section{Recommendations}

In view of the findings of the study, the following recommendations were submitted: In as much as there is no relationship in the achievement in auditory discrimination that existed between the musical interest and mental ability of the pupils any child therefore can be helped to develop the proper musical interest to achieve the goals of music education in the elementary level. This can be achieved by means of the following:

1. Pupil should be property exposed to good music through organization of glee clubs, rondallas, musical contest, attending concerts, and the like.

2. In as much as music requires special skills, not all teachers can teach music. The administrators, therefore, may conceive of plan where in their schools can provide special music teachers.

3. To provide the proper musical environment in the classroom, music teachers should be carefully selected on the basis of a clear-cut criteria which include the following among others: a. voice and ears for music; b. ability to play any musical instruments; c. ability and interest in creating music.

4. Music teachers maybe assisted to improve in their competencies through a year-round in-service education, attendance in short-term courses, scholarships, etc.

5. In case of pupils, their potentials may be challenged by means of participation in music contest; creative song-writing and interpretation and similar activities. From there, musical interest and potential can be discovered and then, developed.

6. In as much as the findings of this study were not conclusive, the following are recommended: 
- A similar study in a different environment.

- A replication of the study, using the following variables; high mental ability, high socio-economic status and high interest in music.

- Similar studies using age and sex as the variables correlated with musical interest.

- Strengthen the music education awareness in college in adequately prepare the would be teachers to teach music correctly and effectively.

\section{REFERENCES}

Bergethon, B., Boardman, E., and Montgomery, J. (1986). Musical Growth in the Elementary School. New York: Holt, Rinehart and Winston.

Drake, R. (1980). Drake Musical Aptitude Tests LP Record and Test Manual. Chicago: Science Research and Associates, Inc.

Freedom, J. (1980). Introductory Psychology. Philippines: Addison Wesley Publishing Co.

Garry, R., \& Kingsley, H. L. (1970). The Nature and Conditions of Learning. Englewood Cliffs, NY: Prentice-Hall.

Juan, J. C. (1980). The Music Education Program in Pasig. Unpublished Master's Thesis, Ortanez University, Quezon, Philippines.

Kelly, W. A. (1982). Educational Psychology. Garden City, NY: Adelphi University Libraries.

Marvin, C., Alkin, N. J., and Karen, R. (1992). Encyclopedia of Educational Research. NY: Michele.

Miner, B. (1968), Sociological background variables affecting school achievement, Journal of Education Research, 61(8), 372-381.

Samonte, T. M. (1990). Achievement Level in Communication Arts English of Second Year Student and Some Selected Factors. Unpublished Master's Thesis, Philippine Christian University, Manila, Philippine.

Yotonghot, S. (1986). Age and Performance Level in the Non-Formal Occupational Program of Ban Vinne Refugee Camp St. Looie Thailand. Unpublished Master's Thesis, Thaksin University, Southern Thailand. 
